\title{
Convergence of Activity of the Creative Elite on the Basis of Self- Realization of Personality
}

\author{
Stoyanova Linda Leonidovna \\ postgraduate student of the Chair of Philosophy, Sociology and Social and \\ Cultural Management of the State Institution "The South Ukrainian National \\ Pedagogical University. K.D. Ushinsky", Odessa.
}

\begin{abstract}
The main idea is revealed that the creative elite of Odessa South Ukrainian School of Painting is a significant phenomenon of all social life, plays an important role in the life of society, and has a multifaceted impact on the whole life of social space. It is revealed that in the case of the creative elite, its influence on the formation of a particular social space occurs in an ideal sphere at a complex level, and the essence of this influence is determined by the essential "value" characteristics of representatives of the creative elite. It is noted that the Odessa creative elite can be considered as a carrier of a set of social, ethical, psychological, spiritual ties and relationships, it should be defined as the national elite - the creative national elite. It is substantiated that the functional characteristics of the elite representatives, who form a special social space, are the organizing force that makes any society an integral socio-cultural system.
\end{abstract}

Keywords: creative elite, Odessa school, creative social space.

Introduction. The multivariate social processes of the present arouse interest in the creative elite, which demonstrates high achievements in creativity and leads a constant search for new patterns and guidelines that can be the basis for the development of all structures of society as a whole. The relevance of the study of this problem lies in the fact that without the creative elite, the flowering of culture is impossible, and the problem of the nation's selfawareness, the quality of communication, and the spiritual atmosphere in society are associated with the qualitatively expressed potential of the creative elite.

Need is to comprehend and understand the spiritual world of the creative elite and, in particular, one of the most important components of which is the sphere of not only artistic creation, but also the basis for the formation of a special creative social space.

The degree of elaboration of the problem. The problems of the elite are characterized by the contribution to the solution of the studied problem of thinkers who worked at the intersection of sociology, psychology and philosophy. In the historical context, the 
philosophical idea of the creative elite, understood not only as an integral part of the hierarchical structure of society, but also as ideas for the spiritual improvement of man, originates in the writings of Pythagoras, Plato, who considered this hierarchy as a derivative from the spiritual (including moral) personality traits. The concept of Plato was developed by philosophers of the following eras: ancient - such as Aristotle, Seneca, Plotinus, Proclus, medieval - Augustine, Thomas Aquinas, Roger Bacon, Renaissance and the New Age - N. Machiavelli, J. Bruno, F. Bacon, T. Hobbes, Pico della Mirandola, Erasmus of Rotterdam, J. Locke, Leonardo da Vinci, J. Vasari, Scaliger; Recent times - I.G. Fichte, A. Schopenhauer, L. Feuerbach, F. M. Dostoevsky, V. S. Soloviev, P. Teilhard de Chardin, J. Dewey, K. Jaspers, M. Heidegger, J. P .Sartre, M. Young. In the works of I. Kant, J. Russo, F. Schelling, F. Nietzsche, it is significant that everyone represented the idea of the historical mission of the human mind, which passed in its evolution from clearly optimistic to pessimistic self-esteem. An analysis of the phenomenon of the elite as a creative active minority in the context of the development of culture and civilization is made in the works of O. Spengler, A. Toynbee. An important role in developing understanding of the creative elite also belongs to N.A. Berdyaev and H.Ortega-iGasset.

Insufficiently lit parts of the problem. Despite a sufficient number of works on the elite and elitism, it is necessary to synthesize them and build a concept based on the idea of the innovative capabilities of the creative elite as representing a special social space.

The purpose of the study is to consider the activities of the creative elite in society and the disclosure of its qualitative characteristics. To justify that the creative elite creates a special social space and identify its functional characteristics.

The main content (research methodology). At the moment, there are concepts and theories of elites that have their own ideas about this social institution. In the twenty-first century, the theory of elites can be considered in a more special social context than previously. The main existing schools in the study of elites are monistic and pluralistic with the inclusion of functional and value approaches. Proponents of the value approach develop the idea that the elite are people who have special qualities. The elite is treated as a layer of society, united on the basis of concern for the common good. The authors of civilizational theories considered ongoing social, economic, political processes as development initiated by the elites. From the 
point of view of the modern synergetic approach, the characteristics of subjects with high cognitive structured thinking are decisive for the elite; representatives of the elite are not a separate stratum, but individuals located at all levels of the hierarchy of the social pyramid.

The main content (Discussion). The creative elite of Odessa South Ukrainian School of Painting is a significant phenomenon of all social life, which plays an important role in the life of society, have a multifaceted impact on the whole life of society as a whole. In the case of the creative elite, its influence on different aspects of the life of the society occurs in an ideal sphere at a more complex level, and the essence of this influence is determined by the essential "value" characteristics of representatives of the creative elite. Odessa's creative elite can be seen as a carrier of a set of social, ethical, psychological, spiritual ties and relationships, it should be defined as the national elite - the creative national elite.

It is possible to turn to the conclusion of the modern Ukrainian researcher Z. Atamanyuk, who notes that in the context of considering "the influence of the concepts of the national elite on the formation of Ukrainian statehood, it turns out that on the Ukrainian soil the problem of the elite has its own specificity. In the conditions of Ukraine's statelessness, there is every reason to say that its elite existed. It did not perform a managerial function because there was no state. But the elite of Ukraine has managed to realize itself without the state "[1]. According to Z. Atamanyuk, "a new reading of the role and functions of the national elite is connected with significant changes and transformations in the social structure. During the critical period of development of Ukrainian society, the elite was not able to solve the problems positively. Transition conditions in Ukraine have adversely affected the balance of elites. Today in Ukraine the dominant role is played by the political elite, which negatively affects the spiritual and cultural life of Ukrainian society. Therefore, it is advisable to distinguish between the elite of the stable period of development of society and the elite of the critical phase of development of society "[1]. Identifying the factors of influence of the creative elite on the creation of a special social space, we are in agreement with Z. Atamanyuk's position on the expediency "to consider transformation from the point of view of the phenomenological approach, the game concept. This will reveal a kind of scheme, a model of change that has taken place with the elite during the transformation crisis. Inclusion in the game is considered as an opportunity for the individual to go beyond the ordinary, to break away from the usual and standard, to dissolve in 
the spatio-temporal sphere of activity. The game mechanism is capable of establishing new spiritual and social connections. It creates the illusion of excellence that is focused on real possibilities. It is this kind of game that embodies the essence of the person playing (Homo Ludens), carries the content of the creator of new social relations and forms, ways of movement of the society"[1].

In exposing the influence of the creative elite on the creation of a special social space by the example of the South Ukrainian school of painting, we were guided, first of all, by the position that this creative elite is the bearer of a certain set of social, ethical, psychological, spiritual ties and relationships, which determine the factors formation and formation of a very special social space. Secondly, Odessa is a cultural city that always has a special style in all socio - cultural manifestations. The traditions of the City, related to its cultural myth, which combine with the intellect and cosmopolitanism kindness, humor and tolerance, and where painting was no exception, but in addition to all this, largely determined the features of "Odessa painting - a special style, where in the works always reflect the southern charm, European glamor and chamber elegance.

For P. Bourdieu, the creative elite is characterized by "the desire to accumulate knowledge and skills is inseparable from the search for recognition and the desire to create a name for yourself" [2, p. 132]. The specificity of the field of cultural production consists in a combination of two components: power and semantic relations. If the former are manifested as competition, the struggle for the monopoly of possession of dominant positions, for recognition, the latter are built on the basis of the opposition of styles, trends, forms of communication accepted in this field. Competition for legitimate dominance in the field, which takes the form of a struggle for one's own authority and attempts to undermine the authority of others, leads to constant changes in its configuration. A writer or an artist creates not only for the public, but also for his colleagues acting as competitors. The rivalry in the field of culture "produces a specific form of interest, which seems disinterested only in comparison with ordinary interests, especially to power and money, and is aimed at gaining a monopoly on authority, where technical competence and symbolic power are closely intertwined" [2, p. 131]. In the field of literature, P. Bourdieu emphasizes, as well as in any other field of cultural 
production, there is an opposition of "masters," carriers of tradition representing the dominant trends and genres, to "newcomers" working in new, marginal genres and styles [2, R. 131].

To substantiate our assumptions about the features of social space, and based on the concept of our research, we turn to R. Florida's work on the "creative class" by which we understand the creative elite. According to R. Florida, "the peculiarities of the post-industrial economy of cities are that" the more mobile everything becomes, the more decisive the city becomes. Cities are not just a repository for smart people, but a conducive infrastructure in which connections are made, contact networks are created and a fundamentally new mix is formed. The most valuable characteristics of cities are not basic services or economic opportunities, but the objects of social and infrastructure of the city, its goodwill and beauty. It shows that factors such as involving large companies in the city, active participation in the civil society institutions of its inhabitants, close social ties, uniting the urban community are no longer the key to economic success. More important is the creation of comfortable conditions for professionals of the "creative class" (R. Florida term), whose presence in the city directly depends on its development "[2].

The significant consequences of the influence of the creative elite on the creation of a special social space are the following: the creation of a new organization that created a new artistic and aesthetic space (Society in Odessa on the initiative of a group of local artists led by N. Skadovsky); the continuation of the tradition of bringing art to the masses (the founders of TPRC were, above all, followers, and many members of the Association of Mobile Art Exhibitions); the formation of a new communicative structure, which, of course, in image, reflected on the idea in society of the lives of artists (in TPRH consisted of artists, close and creative and in spirit, united by a sense of friendship and mutual sympathy. Hence the longstanding informal gatherings of South Ukrainian, famous Ukrainian "Thursdays". At these evenings music was played, poems were read, cartoons were drawn to each other, fun draws were made); philanthropic activities that fostered a positive attitude towards the arts - artists (the Society organized annual charity balls, which were decorated with great fiction, for example, in "Egyptian" or "Chinese" styles); public activity that supported relationships and relationships in society (artists participated in charity auctions, amateur performances, performed at meetings of literary, artistic, photographic and other societies); introduction of the 
idea of involving the masses of artists with different preparation for creative work; expanding ties and contacts with other art elite regions (Odessa artists and sculptors tried not to be locked in a narrow, small provincial world, focused on the artistic life of major cultural centers); attention to art education and continuous professional development (traveling abroad for educational purposes; some artists received professional training at the St. Petersburg Academy of Arts, art schools and academies in Germany, Italy, France; a certain seclusion of social space the works of the South Ukrainian artists - exhibitions of their works, if you believe the reviewers, became less and less interesting from year to year, not because the level was falling, but because there was no movement forward); mutual assistance in their professional environment (the situation in Odessa did not greatly contribute to the prosperity of art: the indifference of the public, the narrow circle of collectors and philanthropists, potential buyers of paintings and sculpture, the very atmosphere of a large shopping city, where business has always preferred culture. not only did they support and assist in exhibiting their works, but, most importantly, they contributed to their sale, because most of the artists, with the exception of a few wealthy ones, lived mainly through professional work and teaching (K. Kostandi, T. Dvornikov); association based on community in elementary art education (almost all Odesa participants of periodic exhibitions were students of the Odessa Art School (since 1900 - art school); freedom of artistic views and expression (the school was dominated by the spirit of democracy and relative freedom of views, for example. that in $1910 \mathrm{D}$. Burlyuk returned to the art school to receive his diploma (he began his education in 1899-1900), by that time he was already scandalous and was accepted despite the negative attitude of K. Costandi and the director of the school. A. Popov to all manifestations of "modernism"); leveling of professional and creative secrecy (one of the indisputable advantages of TPCRC was the lack of caste seclusion, openness to all who want to participate in exhibitions - from venerable academics to young students, students of Odessa schools; , formation and establishment of a special Odessa plein air painting school (tradition lives in time, passed from master to student. And today, plein air for the Odessa painting school continues to be one of the main characteristic features the qualities that shape her personality); Art traditions from the past pass over to our time ("Society of South Ukrainian Artists" and "Society of Independent Artists" have defined the following two trajectories of the art movement of Odessa. In the 60s of the last century there is 
a "second wave of avant-garde", though, of course, it arises far beyond the Union and even in support of it, however, those who started this long-standing tradition have long been members of the Union and its leading bright figures (members of the Mamay Art Association).

Conclusions. On the basis of the analyzed material it is possible to make certain generalizations and conclusions.

It follows from history that, despite the different social and historical circumstances, the influence of the South Ukrainian School of Painting - its creative elite - was constantly felt on the creation of a special social space not only in Odessa, but this influence eventually spread to all territories. Influence of the South Ukrainian School of Painting of the XIX-XXI centuries. as a creative elite to create a special social space, reveals the convergence of the creative elite on the basis of self-realization of the individual.

The elite, as a social entity that preserves existing values or forms new ones, determines the history of the community to which it belongs. It is possible to consider the creative elite as the bearer of the totality of certain social, ethical, psychological, spiritual ties and relationships. The creative elite, as an integral part of the elite, acts as an independent objectively existing phenomenon of social life, which plays an important role in society, has a diverse effect on both the spiritual and other components of the life of the elite and society as a whole. It is proved that the functional characteristics of the elites are the organizing force that makes any society a holistic sociocultural system. In this context, the creative elite can be seen as the bearer of the totality of certain social, ethical, psychological, spiritual ties and relationships. Without the creative elite, neither the flourishing of culture, nor education is possible, and the position and quality potential of the creative elite are connected with questions of the nation's identity, the quality of communication, the moral and spiritual atmosphere in society. The impact of the creative elite on different aspects of society's life takes place in an ideal sphere on a more complex level, and the essence of this impact is determined by the essential "value" characteristics of the representatives of the creative elite.

Prospects for further research. As a prospect for further research of the ethics of the creative elite within the framework of the general theoretical orientation of understanding the creative elite, we can call an analysis of the content and mechanisms of the influence of the creative elite both on the elite in a broader sense and on society as a whole within the 
framework of the dichotomy of the elite - the mass, taking into account features of the postindustrial and information society.

\section{References}

1. Atamanyuk, Z. M. (2003) Social and philosophical concepts of the Ukrainian national elite / Zoya Mykolayivna Atamanyuk: Author's abstract. dissertation Candidate of Science in Philosophy 09.00.03 - Social Philosophy and Philosophy of History. Odesa. - 32 p.

2. Bourdieu, P. (1996) Social space and the genesis of "classes" // Bourdieu P. Sociology of Politics. M.. - P.55-97.

3. Florida, R. (2016) Creative class: people who change the future / Richard Florida. M .: Mann, Ivanov and Ferber. $\quad 384$ p. 